Jing met verwehillende rantsoenen, kennis vereischte van krijgskunde, vestinglouw of voedselleer, cvenmin behoeft men een syllabe van bedrijfsleer of accountancy te weten om het besproken vraagstuk op te lossen. Common sense om de opgaaf te begrijpen en verder algebra en accuratesse zijn volop voldocnde.

Toegcgeven moet worden, dat de opgaaf niet eenvoudig is gesteld en zelfs op enkele punten cenigszins misleidend is, zoodat hicr inderdaad een mocilijkheid meer aanwezig is. Maar het komt ons voor, dat examenopgaven vóór alles duideljjk moeten zijn, en niet zoo bedenkelijk als hier op puzzles mogen lijken.

Wij meenen, dat in het algemeen bij statistick-vraagstukken geen gespecialiseerde kennis vereischt is en zelfs niet van statistiek, indien men alle begrippen in het vraagstuk definieert. Indien wij een serie getallen geven met de opgaaf, daaruit b.v. den mediaan of den modus te bepalen, dan is daarvoor noodig kennis van begrippen, die bij de statistische methode worden gebruikt. Indien wij echter die begrippen gelijktijdig definieeren is het vraagstuk uitsluitend mathematisch.

Statistick-vraagstukken hebben derhalve alleen beteekenis, indien ze zich bepalen tot toetsing van de kennis van begrippen die bij de statistische methode zelf te pas komen. Wanneer dit nict meer het hoofddoel is gaat het feitelijk nict meer over statistiek, doch over mathematica.

Op bovenstaande gronden komt het ons voor, dat vraagstukken als het besprokene niet vallen binnen het kader der vakexamens voor accountant.

F.F. van DOORNE.

\section{FINANCIEELE AANSPRAKELIJKHEID VAN DEN ACCOUNTANT INGEVAL VAN FRAUDE IN EEN DOOR HEM GECONTROLEERD BEDRIJF.}

Onlangs is in Ned. Indië een vonnis uitgesproken tegen cen accountantskantoor, dat beschuldigd werd van nalatigheid in de uitvoering van cen contrôle-opdracht. Wij mcenen dat, daar zoo zelden zulk een uitspraak in ons land voorkomt, het, wel van belang voor onze lezer's is daarvan kemnis te nemen en publiceeren het daarom onverkort, met weglating der namen. Om misvel'stand te voorkomen, deelen wij mede, dat het accountantskantoor, dat voor sehadevergocding werd aangesproken, niet van Nederlandsche nationaliteit was.

Thans volgt het vonnis:

Overwegende eerst en vooraf, dat de door den procureur vall eischer, $\mathrm{Mr}$. H., gevraagde acten kummen worden verleend evenals de door partijen gevraagde acten van bewijsaanbod;

Over'wegende, dat eischer, stellende,

dat gedaagde, vanaf April 1927 in opdracht van eischer de boekhoudkundige en financiecle leiding alsmede de controble over eischers bedrijf heeft gevoerd tegen de in den eisch gestelde honoraria, die alle zijn voldaan behoudens die voor het jaar 1932 ad $f$ 1.100. - in totaal;

dat gedaagde verzuimd heeft de bocken van eischers kantoor gedurende de jaren 1928 tot en met 1931 en gedurende de ecrste zeven maanden van het jaar 1932 geregeld en behoorlijk te controleeren :

dat hicrdoor $\mathrm{T}$. als boekhouder tevens kassier op eischers kantoor gelegenheid heeft gehad tusschen 1 Januari 1928 en 29 Juli 1932 een bedrag van $f 13.426 .79$ ten nadeele van eischel te verduisteren;

dat 'T. deze verduisteringen heeft kunnen plegen, omdat gedaagde gedurende bovengenoend tijdvak heeft verzuimd de ontvangstposten in eischers kasboek te vergelijken met de souches van eischers kwitantieboeken;

dat deze fraude pas op 29 Juli 1932 door gedaagdes accountant $B$. is ontdekt bij vergelijking van het kasbock met de souches der kwitantieboeken;

dat de fraudes reeds bij den aanvang crvan zouden zijn ontdekt, indien de voorgangers van den accountant $B$. eveneens het kasboek met de kwitantie-souches hadden vergeleken;

dat het nalaten hiervan wanprestatie van gedaagde oplevert in de tenuitvoerlegging van de tusschen partijen bestaande overecnkomst, althans cen onrechtmatige daad van gedaagde;

dat gedaagde door deze nalatigheid an eischer ecn schade heeft veroorzaakt van $f$ 13.462.79, die zij verplicht is aan eischer te vergoeden, doch gedaagde betaling heeft geweigerd; dat dit bedrag met het door eischer aan gedaagde verschuldigde honorarium moet worden verminderd;

van den Raad vordert bij vonnis uitvoerbaar bij voorraad gedaagde te veroordeclen om tegen behoorlijke kwijting aan eischeres te betalen de somma van $f$ 12.362.79 (twaalf duizend drie honderd twee en zestig gulden negen en zeventig centen) met de wettelijke rente ad $6 \%$ 's jaars vanaf den dag der dagvaarding tot op dien der algeheele voldoening toe;

Overwegende, dat als door gedaagde erkend rechtens vaststaat, dat T. ten nadeele van cischer een bedrag van $f$ 13.462.79 hoeft verduisterd;

Overwegende, dat gedaagde echter heeft ontkend zich aan wanprestatie te hebben schuldig gemaakt en in het bijzonder heeft ontkend, dat tusschen partijen is overcengckomen, dat gedaagde de boekhoudkundige en finaneicele leiding en contrôle zou voeren over eischers bedrijf, daar eischer de bockhoudkundige en financieele leiding van zịn zaken, voorzoover niet door hem zelf gevoerd, heeft overgelaten aan zijn bockhouder K. en deze aan den klerk 'T., dic belast was met het incassecren van rekeningen, het uitschrijven der kwitanties en der daarlij behoorende souches, overlict en zelfs van tijd tot tijd het inschrijven van eischer's kasbock, hebbende gedaagde verder gesteld, dat zij in opdracht van eischer in de jaren 1927 tot en met 1931 één maal per jaar en na ontdekking der fraudes halfjaarlijks eischers boekhouding door middel van een harer accountants aan cen onderzock heeft ondel'worpen, teneinde voor eischer na te gaan, of zijn bocken wel richtig door zijn boekhouder werden bijgehouden, wa arover gedaagde dan telkens aan eischer rapport nitbracht en zulli een éénjaarlijksch onderzoek niet impliceert, dat de accountant belast is met de boekhoudkundige en financiecle leiding en controble over het bedrijf van den opdrachtgever;

overwegende ten aanzien van dit geschilpunt tusschen partijen betreffende den inhoud van de overeenkomst,

dat eischer geacht moet worden de door hem bij conclusies van eisch en repliek in het geding gebrachte accountantsiapporten van gedaagde, jaarlijksche winst- en verliesrekeningen en balansen te hebben overgelegd tot bewijs van de door hem gestelde overcenkomst tussehen partijen;

dat echter deze geschriften niet de loor: hem gestelde over eenkomst bewijzen, doch wel de door gedaagde gestelde beperkte contrôle-overcenkomst ;

dat toch door voormelde geschriften rechtens is komen vast te staan;

1e. dat gedaagde over het boekjaar 1926 voor eischer heeft opgemaakt een balans en winst- en verliesrekening per ultimo 1926 alsmede cen rapport, houdende toclichting op evengenoemde stukken en de door haar tot het samenstellen ervan verrichte werkzaanheden;

2e. dat gedaagde over de boekjaren 1927 tot en met over 1931 
ten behoeve van eischer dezelfde stukken als over het boekjaar 1926 heeft opgemaakt en aan eiseher ingediend,

Overwegende, dat de aard van de overeenkomst met een accountant tot contrôle van een bedrijf kan varieeren vanaf ecn geregelde dagclijksche dan wel wekelijksche of maandelijksche contrōe, waarbij de accountant de hoofdboeken bijhoudt tot aan de verplichting van den accountant om de boekhouding telkens ten aanzien ran cen bepaald boekjaar te controleeren en uit de boeken cen balans on winst- en verliesrekening samen te stellen, die dan vergezeld van een toelichtend rapport moeten worden ingediend;

dat door de door eischer in het geding gebrachte zooeven genoemde stukken duidelijk reehtens is aangetoond, dat tusschen partijen heeft bestaan een overeenkomst van den geringen omvang als zooeven het laatst genoemd;

dat ook het door eischer in het geding gebrachte rapport van de accountants-firma $F$ houdende verklaring van deze firma op welke tijdstippen gedurende de bockjaren 1927 tot en met 1932 gedaagde eischers boeken heeft onderzocht, geen afbreuk doet aan de conclusie, dat tusschen partijen cen overeenkomst bestond van evengemelden geringen onvang, doch dit rapjort deze conclusie juist bevestigt ;

dat toch uit voormeld door gedaagde niet weersproken rapport blijkt, dat gedaagde voor het bockjaar 1927 pas op 23 Augustus 1927, voor het bockjaar 1928 op 14 Augustus 1928, voor het bockjaar 1929 pas op 17 November 1929, voor het bockjaar 1930 pas op 23 Augustus 1930, voor het boekjaar 1931 pas op 19 September 1931 en voor het boekjaar 1932 pas op 29 Juli 1932 cen aanvang heeft gemaakt met haar werkzaamheden betreffende het telkens loopende boekjaar, terwijl, indien cen overeenkomst was gesloten als door eischer gesteld, gedaagde niet voortdurend de eerste zes maanden van ieder boekjaar ongecontroleerd zou hebben gelaten en eischer daartegen zekerlijk zou hebben geprotesteerd en zelfs hebben moeten protesteeren voor handhaving van zijn rechten;

dat, nu hiervan ten processe is gebleken, het feit, dat gedaag. de steeds pas na afloop van het cerste halfjaar met de controlewerkzaamheden een aanvang maakte en die dan blijkens voormeld rapport van $F$ door nog éénmaal of enkele malen contrôlewerk over elk lookjaar te verrichten beëindigde, mede rechtens bewijst, dat tusschen partijen slechts bestaan heeft een overeenkomst van jaar-eontrôle met verplichting van gedaagde om een balans en winst- en verliesrekening met toclichtend rapport over elk boekjaar op te maken;

dat hieraan ook niet afdoet, dat gedaagde gedurcnde het loopende bockjaar meer dan één keer contrôlewerk verrichtte, daar gedangde terecht heeft aangevoerd, dat haar cigen bedri.jf niet goed zou kunnen worden uitgeocfend, indicn zij. bij al hare cliënten met den aanvang van haar contrôlewerk zou wachten tot na afloop van het te controleeren boekjaar;

dat toch algemeen bekend is, dat een accountant, die met jaarcontrôle belast is, eindeijfers trekt uit de door hem gecontrolecrde bockposten vanaf het begin van het te controleeren bockjaar tot het moment, warop hij met de controle aanvangt en bij de tweede en eventueel volgende controle voor dat bockjaar voortbouwt op deze telkens door hem getrokken eindcijfers :

dat eischers bewering bij repliek, dat T. maandelijks cen balans opmaakte met bijbehoorende debiteuren- en erediteurenstaten en deze geschriften door gedaagde werden gevraagd, evenmin afbreuk doct aan het vooroverwogene, daar gedaagde deze geschriften kon aanwenden bịj haar contrôlewerk, terwịj1 het opviagen van deze staten op zichzelf allerminst contrôlewerk kan worden genoemd; en ook gcen argument oplevert voor de stelling, dat gedaagde geregeld moest controleeren, daar dit laatste alleen door cigen inzage van eischers boeken en bescheiden door gedaagde kan worden verricht;

Overwegende alsnu ten aanzien van de verplichtingen van gedaagde in de overeenliomst zooals de Raad rechtens aanneemt, dat zij tusschen partijen heeft bestaan,

dat gedaagde heeft beweerd:

1e. dat een controlecrend accountant nict verplicht is als ecn detective op te treden en zijn werk te doen met wantrouwen in het personeel;

2c. dat de accountant mag afgaan op de opgaven van het personeel, dat, zooals in casu van $K$, een vertrouwenspositie inneemt, en de accountant alleen verplicht is zijn onderzoek ten gronde toe voort te zetten, indien zich bij de contrôle iets voordoet, dat zijn verdenking moet gaande maken ;

3e. dat gedaagdes accountant, die eischer's boekhouding onder zocht, redelijkerwijs mocht aannomen, dat K. zijn dagelijksche taak van bockhouder on van kasbeheerder in eischers bedrijf onder rechtstreeksch toczicht van eischer volbracht;

4c. dat gedaagdes accountant mocht afgaan op eischers telkenmale gedane verzekering, dat de uitstaande vorderingen door hem goed en verhaalbaar werden geacht en eischer hiermede gedaagde onthief van een nader onderzock van den stand der debiteuren-rekening;

Overwegende ten aanzien van dit alles,

dat geclaagde, die tot taak had het bedrijf van eischer te controlceren en een jaarlijksche balans en winst- en verliesrekening uit de door haar gecontroleerde boekposten aan de hand van de aanwezige bescheiden te controleeren;

dat toch de balans en de winst-en verliesrekening ecn volkomen juist beeld moeten geven van den stand der zaken per ultimo December van elk boekjaar;

dat, om hiertoe te kunnen geraken gedaagde een geheel zelfstandige plicht had alle bockposten te controleeren aan de hand van de aanwezige bescheiden en verantwoordingsstukken;

dat deze verplichting ten aanzien van een of ander bedrijfsonderdeel pas zou komen te vervallen, indien eischer zelf gedaagde uitdrukkelijk zou hebben ontslagen van haar plicht, dat bepaalde onderdeel te controleeren;

dat zulk een controleeren van boekposten aan de hand van de bescheiden mocilijk detectivewerk kan worden genoend, daar dit niets meer is dan een voldoen door gedaagde aan de op hadr rustende plicht tot volledige controle en deze plicht gehcel zelfstandig staat, los van welke verplichtingen ook, die op eischers personeel als werknemers rusten;

dat een mededeeling van eischer zelf, dat de in zijn boeken roorkomende debiteuren goed zijn, niets afdoet aan gedaagdes plicht te controleeren, of de vorderingen op debiteuren zooals zij per ultimo December van het boekjaar in de boeken voorkomen, in werkelijkheid nog bestaan, daar nu cenmaal de balans en de winst- en verliesrekening per ultimo December van een boekjaar een juist beeld moeten geven van de bedrijfsverrichtingen in het gecontrolecrde jaar;

Overwegende, dat gedaagde heeft erkend, dat haar controleerende accountants wat betreft de contrôle over de jaren 1928, 1929, 1930 en 1931 niet de souches der kwitantie-boekjes hebben vergeleken met de ontvangstposten in het kasboek;

Overwegende, dat dit een schuldig nalaten van gedaagde is in de tusschen partijen door den Raad vastgestelde controleovereenkomst, daar, zooals reeds overwogen, gedaagde de zelfstandige plicht heeft alle bockposten van het boekjaar, dat gecontroleerd wordt, te verifieeren met de aanwezige bescheiden, derhalve ook de posten in het kasboek met de aanwezige kasverantwoordingsstuklien en als zoodanig voor de ontvangst- 
posten in het kasboek o.m. de souches van de uitgeschreven kwitanties mocten dienen;

Overwegende, dat de bewering van gedaagde, dat deze souches, nu de kwitanties zonder toczicht door $T$. zelf werden uitgeschreven, elken waarborg van juistheid misten, niet opgaat, daar gedaagde door deze souches te verificeren met de geschriften - namelijk copie-facturen en copie-volgbriefjes bijvoorbeeld - aan de hand waarvan T. de kwitanties moct hebben opgemaakt, ook de juistheid dier souches kan controleeren;

Overwegende, dat in verband met het zooeven overwogene ook gedaagdes bewering bij dupliek, dat cen systematisch onderzoek der souches geen waarborg zou hebben kunnen geven, daar de kwitantie-boekjes voor een ieder toegankelijk waren in handen van den rekeninglooper, niet opgaat en waardeloos is ;

dat inderdaad, zooals gedaagde bij dupliek mede heeft beweerd, de meest nauwkeurige controle is een onderzock bij de debiteuren zelf, doch dit inderdaad in cen bedrijf als dat van eiseher niet, zooals wel bij bank-instellingen, door het afgeven van saldobiljetten, gebruikelijk is ;

dat echter ecn contröle van de souches met de stukken, aan de hand waarvan de kwitantics annex de souches zijn opgemaakt, alleszins voldoende, maar danook noodzakelijk geacht moet worden, en gedaagdes bewering bij dupliek, dat zekerheid omtrent het vinden van de fraude niet bestond, daar het onderzoek der tallooze souches zich tot het nemen van steekproeven zou hobben moeten beperken, niet opgaat, daar de Raad aanneemt, dat gedaagde tot plicht had de ontvangstposten van het kasboek met de kwitantiesouches en zoo noodig deze souches met de stukken aan de hand waarvan zij waren opgemaakt te verifiecren, wordende het goede resultaat van zulk een controle rechtens aangetoond door het vaststaande feit, dat de accountant $\mathrm{B}$ door de ontvangst-posten in het kasbock met de souches te verifieeren de door $T$ gepleegde fraude heeft ontdekt;

Overwegende, dat ook gedaagdes bewering bij dupliek, dat $\mathrm{T}$ ongetwijfeld ook betalingen heeft ontvangen zonder dat dit in de boeken werd verantwoord of uit de kwitantie-souches kon blijken, haar niet kan baten;

dat het in de eerste plaats niet kan worden aanvaard, dat debiteuren van eischer zonder bewijs van kwijting aan $\mathrm{T}$ betalingen zouden hebben verricht en voormelde bewering van gedaagde ook in strijd is met haar stelling van antwoord, dat ' $\mathrm{T}$ voor alle debitcuren de kwitanties uitschreef en aan $\mathrm{K}$ ter teckening voorlegde;

Overwegende, dat ook gedaagdes beroep op het Engelsehe recht en de Engclsche jurisprudentie betreffende den aard van cen overcenkomst met een accountant tot bedrijfscontrôle niet opgaat, daar op de door partijen hier gesloten overeenkomst het Nederlandsch-Indische recht toepasselijk is;

Overwegende, dat derhalve thans moet worden nagegaan, of het nalaten van het controleeren door gedaagde van de ontvangstposten in het kasboek met de souches der uitgeschreven kwitanties oorzaak is, dat eischer het gestelde bedrag van f 13.462 .79 schade heeft geleden;

Overwegende, ten aanzien hiervan,

dat weliswaar de bij het ingetreden gevolg, namelijk, dat eischer schade geleden heeft, dichtstbijliggende oorzaak is het verduisteren van genoemd bedrag door $\mathrm{T}$, doch als oorzaak van een ingetreden gevolg moet worden aangemerkt alle tot het intreden van het gevolg medegewerkt hebbende factoren, zonder medewerking waarvan normaliter moet worden aangenomen, dat het gevolg niet zou zijn ingetı'eden en door do werking waarvan dus is te voorzien, dat het gevolg kan intreden ;

Overwegende, dat op grond hiervan het niet-controleeren van de souches door gedaagde geacht moet worden zoo sterk naast het verduisteren door $\mathrm{T}$ als oorzaak van de schade aan de zijde van eischer te hebben medegewerkt, dat dit niet-controleeren ook oorzaak is van het lijden van schade door eischer, daar normaliter moet worden aangenomen, dat door controle van de ontvangstposten met de kwitantiesouches de tot liet moment van deze contröle gepleegde verduisteringen zouclen zijn ontdekt en deze verduisteringen hierna geen verderen voortgang zouden hebben gehad zoodat tegenovergesteld het nalaten van deze contrôle oorzakelijk heeft gewerlit tot het wèl-voortduren van T's ver'duisteringshandelingen;

Overwegende echter, dat het vooroverwogene tevens inhoudt, dat de oorzakelijke werking van het nict-controlecren del souches ten aanzien van het schade-lijden door eischer pas een aanvang heeft genomen betreffende de verduisteringen, die T na 14 Augustus 1928 heeft gepleegd, daar gedaagde bij de blijkens het rapport van $\mathrm{F}$ op dezen datum gehouden contróle, de door ' $\mathrm{T}$ in het toen verloopen tijdvak van het jaar 1928 had moeten ontdekken, doch de vóór 14 Augustus 1928 plaats gehad hebbende verduisteringen geen gevolg kunnen zijn van gedaagdes nalatigheid, nu eischer den aanvang van gedaagdes nalatigheid stelt per den aanvang van 1928 en gedaagde krachtens der partijen overeenkomst niet de verplichting had, met hare contrôle-werkzaamheden over 1928 sen aanvang te maken, terwijl eventueel gebrek aan juiste contróle over voorafgande jaren als niet gestcld niet voor beschouwing in aanmerking komt;

Overwegende, dat derhalve het door ' $\mathrm{T}$ na 14 Augustus 1928 verduisterde bedrag rechtens moet worden vastgesteld, daar alleen gedaagdes nalatigheid ten aanzien van de schade gelijk aan dit deel van het door ' $\mathrm{T}$ ' verduisterde bedrag oorzakclijli werkt;

Overwegende echter, dat dit bodrag uit der partijen stellingen niet nauwkeurig is vast te stellen;

dat gedaagde weliswaar bij conclusie van antwoord heeft beweerd, dat het grootste deel der verduisterde posten valt in de periode tusschen medio 1931, nadat gedaagde het boekjaar. 1930 had gecontroleerd, en medio 1932, toen gedaagde de fraudes ontdekte, doch deze bewering, die kennelijk gedaan is on aan te toonen, dat de verduisteringen hebben plaats gehad in een periode, waarin gedaagde in het geheel geen contrôle heeft verricht, niet opgaat, daar het nalaten door gedaagde van de contrôle van de ontvangst-posten met de souches in den tija vallende vóór de periode van medio 1931 tot medio 1932 mede oorzakelijk heeft gewerkt ten aanzien van 'T's verduisteringen gedurende deze laatste periode, omdat deze verduisteringen na eerdere ontdekking van de fraude door voormclde contröle zekerlijk niet meer zouden hebben plats gehad;

Overwegende echter, dat de Raad voormclde bewering nict aldus ten nadeele van gedaagde mag uitleggen, nu eischer uitdrukkelijk heeft gesteld, dat de verduisteringen door ' $\mathrm{T}$ zijn gepleegd in de periode van 1 Januari 1928 tot 30 Juli 1932 en gedaagde zelf hecft erkend, dat $\mathrm{T}$ met de verduisteringen gedurende ruim $2 \frac{1}{2}$ jaar is doorgegaan, terwijl door den inhoud van het strafvonnis, houdende veroordeeling van $\mathrm{T}$ terzake van de geplecgde verduisteringen mede is bewezen, dat do verduisteringen zijn gepleegd in de periode van 1 Januari 1928 tot 30 Juli 1932 ;

Overwegende, dat de Raad, nu elke andere maatstaf ontbreekt, het voor de periode 1 Januari 1928 tot 14 Augustus 1928 door $\mathrm{T}$ verduisterde bedrag, naar billijkheid verhoudingsgewijs zal vaststellen, wat nimmer in het nadeel van gedaagde kan zijn, daar in het begin de verduisteringen geringer zullen zijn geweest dan later, immers in den beginne nog geen reeds bestaande gaten behoefden te worden gestopt;

Overwegende, dat de Raad derhalve voor evengenoemden 
termijn als door T verduisterd aannecmt $\frac{71 / 2}{5} \times f$ 13.462.79= 8

overwogene gedaagdes nalatigheid geen onrzakelijke werking leeft gehad, zoodat geen schadeplichtigheid van gedalagde jegens eischer vool dit bedrag bestaat;

Overwegende, dat dit voor het restant à $f 11.626 .95$ wel het geval is, laar gedagdes nalatigheid oplevert wamprestatic in de contrôle-overeenkomst en deze schade, zooals reeds overwogen, als gevolg dezer wanprestatic moct worden aangemerkt;

Overwegende alsnu ten aanzien van de vraag, of gedaagde tot betaling van dit volle bedrag onder aftrek van de $f 1.100$. ten aanzien waarvan zij cen door eischer niet aangevallen baroep op compensatie heeft gedaan, moct worden veroordeeld;

dat gedaagde zich heeft verweerd met de stelling, dat de verduisteringen door $\mathrm{T}$ en de hierdoor geleden schade geheel aan cischers eigen nalatigheid en schuld zijn te wijten, daar normale contrôle in het bedrijf zelf door cischer en ook door $\mathrm{K}$, wiens nalatigheid ook ten laste van eiseher komt, ten volle is verzuind ;

Overwogende, dat dit beroep, dat tot inhoud heeft, dat alle schade ten laste van eischer zelf moet blijven, geacht moet worden ook het mindere in te houden, n.l. een beroep op het compensatie-beginsel, i.c. het prineipe, dat hij, die schade-vergoeding vraagt voor het gcheel, zoo hij zelf door schuldige gedragingen mede de schacle heeft doen ontstaan, slechts een deel ervan toegewezen kan krijgen, daar hijj zelf mede voor het geheel verantwoordelijk is;

Overwegende, dat deze mede-verantwoordelijkheid van eischer ten volle bestat;

dat toch de dagelijksche contrôle van de binnengekomen gelden aan de hand van de ter incasseering uitgesehreven kwitanties, die de rekeninglooper als betaald niet meer in zijn bezit heeft en de kwitanties, die hijj als nog niet of nog nict gehcel betaald nog in handen heeft, behoort tot de gewone dagelijksche eigen contrôle in het bedrịf, die eischer dan wel $K$ namens hem had moeten verrichten en het nalaten hiervan grof verzuim is, voor de gevolgen walvan eischer geheel mede-verantwoordelijk is ;

Overwegende, dat derhalve naast gedaagdes verantwoorde. lijkheid voor een bedrag van $f 11.626 .95$ op grond van wanprestatie in de contrôle-overecnkomst staat de verantwoordelijkheid van cischer zelf voor het volle bedrag van $f 13.462 .79$ krachtens zijn onrechtmatige gedraging van verwarloozing van alle interne contrôle van ' $\mathrm{T}$ door hemzelf of door $\mathrm{K}$, zoodat met toepassing van het compensatie-beginsel, waarvoor gedaagde voldocnde feitelijke verweers-stellingen hecft bijgebracht, eiseher als hoofdelijk mededebiteur naast gedaagde als debitrice voor het bedrag van $f$ 11.626.95 waarvoor deze latste aansprakelijk is, ten aanzien van dit laatstgenoemde bedrag bestaat en de helft van dit schadebedrag ten laste van eischer moet blịven, alzoo een bedrag van $f$ 5.813.48;

() verwegende, dat derhalve met passeering van alle bewijsaanbod, de eisch voor een bedrag van $f 4.713 .47$ moet worden tocgewezen en het aan de hoofdsom meergevorderde moet worden afgewezen;

Overwegende, dat de neven-vorderingen als op de wet gegrond voor toewijzing vatbaar zijn en de Raad termen aanwezig acht de kosten te compensceren in dier voegc, dat gedaagde bchalve haar eigen kosten de helft van eischers kosten zal hebben to betalen;

Gelet op artikel 58 van het Reglement op de Rechtsvordering; Verleent de gevraagde acton;
Gaat alle bewijsaanbod voorbij;

Wijst den eisch ten decle toc;

Veroordeelt gedaagde aan eischer tegen behoorlijk bewijs van kwijting te betalen de somma van $f 4.713 .47$ (vierduizend zeven honderd dertien gulden, zeven en veertig centens) net de rente daarover berekend naar $6 \%$ is jaars vanaf 28 Marart 1933 tot de voldocning;

Verklaart dit vomnis tot zoover uitrocrbaar bij voorraad;

Wijpt het meergevorderde af;

Compenseert de kosten van het geding tusschen partijen in dier voege, dat gedaagde behalve har eigen kosten van dic van eischer tot heden begroot op $f 567.75$ (vijfhonderd zeven en zestig gulden vijf en zeventig centen) de helft zal hebben te betalen.

\section{UIT HET BUITENLAND \\ Red.: CH. HAGEMAN, Drs. A. TH. DE LANGE, A. M. VAN RIETSCHOTEN en Drs. E. P. M. VAN WAES (Bijdragen en mededeelingen zende men aan den Secretaris der Redactie)}

\section{Aansprakelijkheid van accountants}

De wettelijke aansprakclijkheid van aceountants vormt hier geen onderwerp, dat belang inboezemt. In het Britsehe Rijk cehter, war het beroep onder invloed van de jurisprudentie staat, trekken de ver'slagen der "Cases" groote belangstelling. IIet volgende geval is ook voor ons van voldoende interesse, daar het cen inzicht geeft in de beroepsoprattingen, die aldaar grehuldigd worden.

Het geval speclde zich af in Canada. De statuten del Bluc Band Navigation Co bevatten ecn clausule, dic hocwel dubbelzimnig den accountant kon docn gelooven, dat het toegestain was om gelden aan aandeelhouders ter leen te verstrekken. De manager, een der voomaamste aandeclhouders maakte hiervan dankibar gebruik. Zijn schuld liep op tot ongeveer $\$ 30.000$ - . Deze post was op de Balans verantwoord als Voorschotten aan Aandeclhouders. Een jaal later werd een bedrag van $\$ 25.000$. o o cen afzonderlijlse debiteurenrekening Wester'll Trading Syndicate overgebockt op last van den manager. De accountant, naar deze overbocking bij deze informecrencle kreeg ten antwoord, dat hij geen inlichtingen wilde geven. daar de zaken van strikt vertrouwelijken aard waren. IIij verstrekte echter een schriftelijke garantic voor deze vordering.

Het bleck, dat het Syndicat voor speculatieve doeleinden in het leven was geloepen. Op balunsilatum was een winst gemaakt van \$12.000.-, die als vordering bijgrboekt werd en op de Verlies en Winstrekening werd verantwoord. Het bedrag werd in het volgende boekjaar in de kas gestort.

In het rapport van den accountant was van bovengenoemde transacties niets vermeld. 'T'oen de Company failleerde, bleek, dat de vordering warvoor de manager een garantie had verstrekt niet invorderbaar was.

Hoe luidke nu het oordecl van den rechter? In cerste instantie werd de accountant veroordeeld, daar hịj in zijn taak te kort was geschoten. De Vennootschap, noch de Commissarissen, noch de aandeclhouders hadden gelden beschikbanr gesteld voor speculaticve doeleinden. I) accountant had nagelaten te informeeren naar de bevoegdheid van den manager en was alleen afgegaan op de schriftelijke garantie. Voorts was de juiste financieele positic niet aan aandeelhouders bekend gemaakt, hoewel deze wel aan den accountant bekend was.

In hooger beroep werd deze beslissing echter vernietigd. 1Ict 